\title{
Acute Generalized Exanthematous Pustulosis in a 51-Year-Old Patient under Etanercept Treatment for Psoriasis
}

Luciana Mabel Ferreira Vasconcelos ${ }^{1}$, Fabricia Martins Teixeira ${ }^{2}$, Eudiana Vale Francelino ${ }^{3}$, Thereza Lucia Prata Almeida ${ }^{4}$, Larissa Bomfim Chagas $^{4}$, Jose Telmo Valença $\mathrm{Jr}^{5}$ and Aparecida Tiemi Nagao-Dias ${ }^{6 *}$

${ }^{1}$ Posgraduation Program of Pharmaceutical Sciences, Faculty of Pharmacy, Federal University of Ceara (UFC), Brazil

${ }^{2}$ Central Public Health Laboratory (LACEN), Ceara, Brazil

${ }^{3}$ Faculty of Pharmacy, Pharmacovigilance Center of Ceara, UFC, Brazil

${ }^{4}$ Department of Dermatology, Hospital Universitário Walter Cantídio, UFC, Brazil

${ }^{5}$ Faculty of Medicine, Department of Pathology, UFC, Brazil

${ }^{6}$ Faculty of Pharmacy, Department of Clinical Analysis and Toxicology, UFC, Brazil

\begin{abstract}
Acute generalized exanthematous pustulosis (AGEP) is a cutaneous reaction mostly related to drug, which is characterized by a rapid appearance of fever, erythema, sterile pustules and neutrophilia. We report a 51-year-old female patient who had taken etanercept $50 \mathrm{mg} /$ week for treatment of psoriasis. In the third month of pharmacotherapy, she interrupted the treatment on her own, and consequently, the lesions reappeared. When the drug was reintroduced, it was associated with prednisone $40 \mathrm{mg} /$ day during 5 days. After this period, multiple erythematous and edematous lesions appeared with small non-follicular pustules. Oral corticosteroid was administered and a progressive and complete improvement was achieved. Histopathological findings revealed AGEP. Bacterioscopy of the pustules proved negative. The patient obtained the score 12 according to the EuroSCAR study group, which indicated a definitive diagnosis of AGEP. The criteria for diagnosis were based on morphology, course and histology of the skin reaction. The association between Etanercept and AGEP is an uncommon finding in the literature.
\end{abstract}

Keywords: Etanercept; Acute generalizaded exanthematous pustulosis; Adverse drug reaction

\section{Introduction}

Etanercept is a soluble TNF- $\alpha$ antagonist approved by the United States Food and Drug Administration for treatment of psoriasis, psoriatic arthritis, rheumatoid arthritis, juvenile idiopathic arthritis and ankylosing spondylitis [1]. Acute generalized exanthematous pustulosis (AGEP) is a significant adverse cutaneous reaction [2] characterized by the presence of multiple disseminated sterile pustules located subcorneally in the epidermis associated with fever, massive neutrophilia and sometimes, eosinophilia [3]. This reaction pattern is most often described in association with drugs (90\%), acute viral infections, spider bites and heavy metals. The involvement of drug-specific $\mathrm{T}$ cells in the pathomechanism can be confirmed by positive skin patch tests and lymphocyte transformation tests [2].

Some adverse events related to anti-TNF- $\alpha$ are injection site reaction, drug-induced lupus erythematosus, infuse reactions, vasculitis [4] and secondary infections such as tuberculosis, leprosy, histoplasmosis, coccidioidomycosis and aspergillosis [5]. Cutaneous adverse reactions associated with etanercept include psoriasis form skin reactions [6], generalized exanthema [7], lupus erythematosus-like syndrome [8], leukocytoclastic vasculitis [9] and erythema multiforme [10]. The association between etanercept and AGEP is very uncommon and until now only 1 case has been described in the literature [11]. We report a 51-year-old female patient who had taken etanercept $50 \mathrm{mg} /$ week for treatment of psoriasis and subsequently developed AGEP.

\section{Case Report}

A 51-year-old woman from the state of Ceara, Brazil, with refractory erythrodermic psoriasis and psoriatic arthritis was treated with infliximab in the period from 2008 to February 2010 (infusions of $5 \mathrm{mg} / \mathrm{kg}$ at week 0,2 , and 6 and then every 8 weeks) in association with methotrexate $(7.5 \mathrm{mg} / \mathrm{wk}$ orally). By the fact the patient did not respond to the therapy, treatment with infliximab was discontinued and monotherapy with etanercept (50 $\mathbf{~ m g}$ twice/wk) was initiated in February 2010. Thereafter, in April 2010, the patient interrupted the treatment on her own, with consequent relapse of psoriatic lesions. In May 2010, the etanercept treatment was restarted $(50 \mathrm{mg} / \mathrm{wk})$ coupled with prednisone ( $40 \mathrm{mg}$ /day for 5 days). In June 2010, she presented eruption with non-follicular sterile pustules on a diffuse, edematous erythema accompanied by fever above $38^{\circ} \mathrm{C}$. The treatment with etanercept was suspended. The skin lesions began on the face and intertriginous regions, moving to trunck and lower limbs, and showed a characteristic post-pustular desquamation after few days (Figures 1A and $1 \mathrm{~B})$.

Ciprofloxacin $500 \mathrm{mg}$ three times a day was prescribed before her admission at the hospital. After the patient was hospitalized, the treatment was replaced by cephalotin $3 \mathrm{~g} / \mathrm{day}$, and after by ceftriaxone $2 \mathrm{~g} /$ day. It was supposed that psoriasis had worsened and that she got a secondary infection. Bacterioscopy of the pustules proved negative. The patient experienced fever spikes, chills, hyporexia, edema of the face, upper and lower limbs, and exfoliative erythroderma, which affected the dorsum of hands and feet. Laboratorial parameters on her admission revealed the following results: white blood cell counts $1.16 \times 10^{3} / \mathrm{mm}^{3}\left(4.0\right.$ to $\left.10.0 \times 10^{3} / \mathrm{mm}^{3}\right)$, neutrophils $85 \%(42.2-75.2 \%)$,

${ }^{*}$ Corresponding author: Aparecida Tiemi Nagao-Dias, Faculty of Pharmacy, Department of Clinical Analysis and Toxicology, Federal University of Ceara, Rua Capitao Francisco Pedro, 1210, CEP 60430-370, Fortaleza, Ceará, Brazil, Tel: 5585-3366-8270; Fax: 55-85-3366-8292; E-mail: tiemindi@yahoo.com.br

Received November 06, 2013; Accepted February 04, 2014; Published February 11,2014

Citation: Vasconcelos LMF, Teixeira FM, Francelino EV, Almeida TLP, Chagas LB, et al. (2014) Acute Generalized Exanthematous Pustulosis in a 51-Year-Old Patient under Etanercept Treatment for Psoriasis. J Pharmacovigilance 2: 120. doi:10.4172/23296887.1000120

Copyright: () 2014 Vasconcelos LMF, et al., This is an open-access article distributed under the terms of the Creative Commons Attribution License, which permits unrestricted use, distribution, and reproduction in any medium, provided the original author and source are credited. 
Citation: Vasconcelos LMF, Teixeira FM, Francelino EV, Almeida TLP, Chagas LB, et al. (2014) Acute Generalized Exanthematous Pustulosis in a 51-YearOld Patient under Etanercept Treatment for Psoriasis. J Pharmacovigilance 2: 120. doi:10.4172/2329-6887.1000120

Page 2 of 4

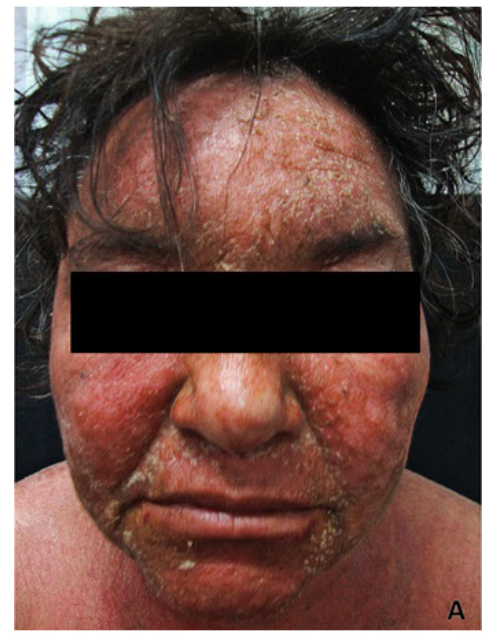

Figure 1a: A 51-year old woman with AGEP caused by etanercept. The patient presented edematous erythema on the face with perioral pustules.

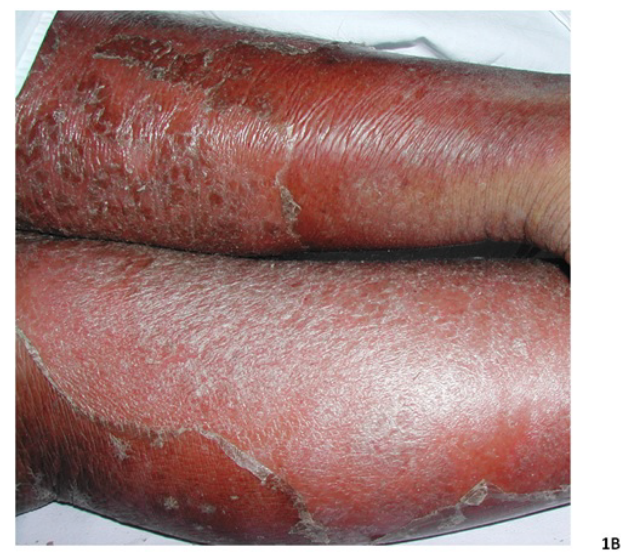

Figure 1b: The lesions progressed to trunk and limbs. A diffuse erythema and swelling, showing a characteristic postpustular desquamation was observed after few days in the lower limbs.

eosinophils $6 \%(0-10 \%)$ and erythrocyte sedimentation rate $70 \mathrm{~mm} /$ hour $(0-30 \mathrm{~mm} / \mathrm{hr})$.

On hospital day 11, the patient complained of nocturnal dyspnea, hypoxia and exacerbation of edema of the upper and lower limbs. Respiratory auscultation revealed pulmonary crackles, wheezing, breathing and tachypnea (respiratory rate: $36 \mathrm{ipm}$ ). Chest $\mathrm{X}$ ray showed pulmonary congestion. A single dose of furosemide $40 \mathrm{mg}$ injected intravenously followed by $20 \mathrm{mg}$ orally every 8 hours was prescribed.

On hospital day 15, the patient had an episode of acute respiratory failure with decreased breath sounds, tachypnea (36 breaths/min) and cyanosis. The patient was stabilized by oxygen therapy and diuretics, bronchodilator and steroids administration. After, antibiotics were administered intravenously (piperacillin $4 \mathrm{~g}$ and tazobactam $0.5 \mathrm{~g}$ three times per day and teicoplanin $400 \mathrm{mg}$ once daily). Culture of lung fluid revealed extended spectrum beta-lactamase Klebsiella pneumoniae.

On hospital day 16, the patient was transferred to the intensive care unit with severe sepsis, acute respiratory failure and pulmonary edema. The patient presented fever, anasarca, generalized scaling and desquamation. After, she developed significant oliguria (100 mL/24h), requiring a larger input of intravenous hydration. The patient developed acute renal failure (creatinine concentration $2.8 \mathrm{mg} / \mathrm{dl}$, serum urea concentration $79 \mathrm{mg} / \mathrm{dl}$ ) and oliguria $(200-450 \mathrm{~mL} / 24 \mathrm{~h})$. Dialysis was required. Doppler echocardiography showed moderate systolic and mild diastolic dysfunction, and moderate anterior septal hypokinesia. At this time, the pustules were resolved spontaneously.

On hospital day 22, the combination piperacillin-tazobactam was replaced by meropenem $1 \mathrm{~g}$ per day. On day 25 , the patient showed slight improvement in the general condition, full consciousness, afebrile, and spontaneous breathing. Nonetheless, the patient remained edematous and anuric (serum creatinine concentration $1.7 \mathrm{mg} / \mathrm{dl}$, serum urea concentration $36 \mathrm{mg} / \mathrm{dl}$ ). Furosemide $40 \mathrm{mg}$ injected intravenously every 8 hours associated with prednisone $70 \mathrm{mg}$ per day was prescribed. After one month of hospitalization, the patient experienced worsening of the psoriatic lesions with disseminated erythematous, crusted plaques on her legs and lamellar lesions on plantar surfaces. She also presented hyperglycemic peaks, lower limb edema, fever and dyspnea. The patient received oral corticosteroids (prednisone $40 \mathrm{mg}$ per day), intravenous corticosteroids (hydrocortisone $300 \mathrm{mg}$ ), topical lotion Lanette, furosemide $40 \mathrm{mg}$ intravenously and powerful antibiotics (teicoplanin $400 \mathrm{mg}$ twice/ day, piperacillin 2.0 and tazobactam $0.25 \mathrm{~g}$, four times per day, and meropenem $1 \mathrm{~g}$ per day). The patient underwent nebulization with bronchodilators and Venturi mask adjuvant oxygen therapy.

In the following days, the patient became afebrile, with resolution of acute respiratory failure. She showed normal respiratory rates and a heart rate around 100 beats per minute. Lower limb edema resolved and the 24-hour diuresis volume normalized. The patient recovered from sepsis. Hemoculture and catheter tip culture were negative. Meropenem and teicoplanin were discontinued after 14 and 21 days, respectively.

The skin lesion biopsy revealed spongiform and intraepidermal subcorneal pustules with papillary edema, intraepithelial collections of neutrophils in the epidermis and lymphomononuclear infiltrates with eosinophil in superficial dermis (Figure 2).

We determined the likelihood of AGEP by use of the European

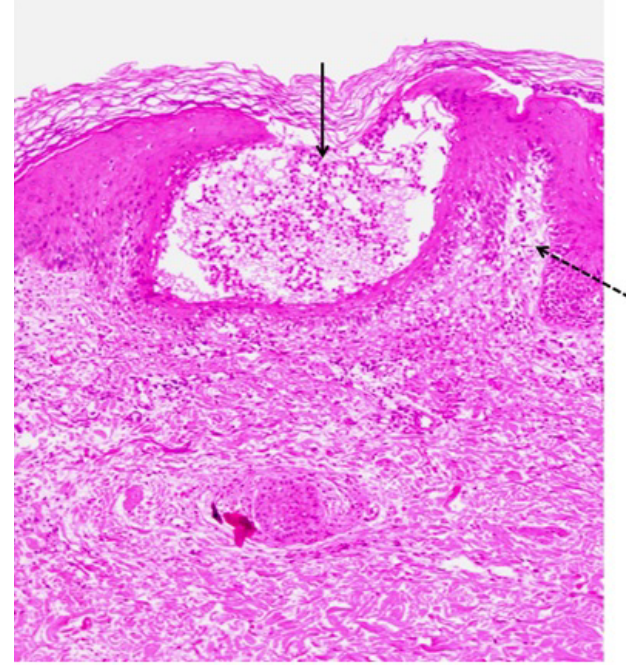

Figure 2: Histopathological analysis of skin biopsy (HE, 400x) showing an intraepidermal pustule containing neutrophils (continuous arrow) with papillary edema (dashed arrow). 


\begin{tabular}{|c|c|c|}
\hline Criteria & Description & Score \\
\hline \multicolumn{3}{|l|}{ Morphology } \\
\hline Pustules & Typical, non-follicular and sterile & +2 \\
\hline Erythema & Typical, diffuse & +2 \\
\hline Distribution/pattern & $\begin{array}{l}\text { face, intertriginous areas, trunk and } \\
\text { limbs }\end{array}$ & +2 \\
\hline Post-pustular desquamation & Yes & +1 \\
\hline Total score & & +7 \\
\hline \multicolumn{3}{|l|}{ Course } \\
\hline Mucosal involvement & No & 0 \\
\hline Acute onset & Yes (few hours) & 0 \\
\hline $\begin{array}{l}\text { Resolution of pustules and } \\
\text { erythema } \leq 15 \text { days }\end{array}$ & Yes ( 15 days $)$ & 0 \\
\hline Fever $\left(\geq 38^{\circ} \mathrm{C}\right)$ & Yes $\left(38.8^{\circ} \mathrm{C}\right)$ & +1 \\
\hline $\begin{array}{l}\text { Blood neutrophil count } \\
\left(\geq 7000 \text { cells } / \mathrm{mm}^{3}\right)\end{array}$ & Yes $\left(13600 / \mathrm{mm}^{3}\right)$ & +1 \\
\hline Total score & & +2 \\
\hline \multicolumn{3}{|l|}{ Histopathological analysis } \\
\hline Skin lesions & $\begin{array}{l}\text { Spongiform sub corneal and } \\
\text { intraepidermal pustules with } \\
\text { papillary edema }\end{array}$ & +3 \\
\hline Total score & & +3 \\
\hline Overall score & & +12 \\
\hline
\end{tabular}

Note: EuroSCAR= European project dedicated to severe cutaneous adverse reactions. Interpretation: score $\leq 0$ indicates no AGEP; 1 to 4 indicates possible AGEP; 5 to 7 indicates probable AGEP; and 8 to 12 indicates definitive AGEP.

Table 1: Scoring system of the Euro SCAR study group for acute generalized exanthematous pustulosis [14]. The scores obtained by the patient are indicated in the last column.

project dedicated to severe cutaneous adverse reactions (EuroSCAR) study group's scoring system [3]. The criteria for AGEP diagnosis were based on morphology, course and histology of the skin reaction (Table 1). Our patient obtained the score 12, which indicated a definitive diagnosis of AGEP. Besides the typical clinical picture, the short course of the reaction was an important clue and one of the major parameters for the AGEP validation score.

The causality assessment by Naranjo's algorithm [12] revealed a score +5 suggesting a probable adverse drug reaction (ADR) to etanercept. The Naranjo scale is a questionnaire for determining the likelihood of whether an ADR is actually due to the drug. The ADR is assigned to a probability category from the total score as follows: definite if the overall score is 9 or greater, probable for a score of 5-8, possible for 1-4 and doubtful if the score is 0 . We considered the following aspects: a) the adverse event occurred after etanercept administration (score: $+2)$; b) the adverse reaction improved when the drug was discontinued (score: +1$)$; c) the patient was receiving etanercept monotherapy when the first symptoms of the adverse reaction occurred (score: +2 ).

The patient was patch-tested with etanercept (Enbrel, New Jersey, United States) 18 months after clinical resolution, according to the procedure done by Seneschal et al. [6].The anti-TNF agent was diluted in $30 \%$ petroleum jelly, and the test was read after 48 hours and on the day 7. The preservatives, color agents and excipients were not tested because they are infrequent causes of delayed cutaneous drug adverse reactions and by the fact they were not available to be tested [13]. The results of patch testing were negative. It is necessary to remind that the patient was under use of adalimumab $40 \mathrm{mg}$ subcutaneous during the period of the patch testing.

\section{Discussion}

The typical clinical picture of AGEP is characterized by a rash with non-follicular sterile pustules on an edematous erythema accompanied by fever above $38^{\circ} \mathrm{C}$. In many cases, the skin lesions involve the face, intertriginous areas, trunk and lower limbs. Mucous membrane involvement may occur in about $20 \%$ of the patients but it is usually mild and remains limited to one site (oral surfaces). The average duration of the manifestations is 9.7 days, followed by a characteristic post-pustular desquamation [2]. Hematologic abnormalities include an increase of blood neutrophils, and sometimes, mild eosinophilia [14].

Histopathological analysis reveals subcorneal pustules with spongiosis. There is edema of the dermal papillae, perivascular infiltrate of neutrophils and eosinophils, and sometimes leukocytoclastic vasculitis, and necrotic keratinocytes [15]. Liver tests are usually normal. Hypocalcemia and mild elevation of aminotransferases can be observed [2].

Recently, Kavala et al. [11] reported the first case of AGEP triggered by etanercept. A 29-year-old man with psoriasis developed erythroderma characterized by tiny pustules after the second etanercept injection. His pustules histopathologic examination revealed subcorneal and intraspinous collections of neutrophils with mild epidermal oedema (spongiosis) consistent with AGEP. Bacterioscopy of the patient's blood and pustules were negative. His general health condition was good. In contrast, our patient developed systemic symptoms including fever, neutrophilia and elevation in the serum creatinine concentration. Additionally, she presented mild acute renal failure, which may occur in one-third of the patients with AGEP [16].

Our patient presented most of the aspects, which characterize the syndrome, that is, lesion morphology, disease course and histological features, according to the EuroSCAR study group [14].

The differential diagnosis included pustular psoriasis and follicular eruptions. The presence of sterile pustules located mainly in intertriginous areas, together with the histopathologic features, were crucial for diagnostic certainty. Late-onset sepsis was probably related to Klebsiella pneumoniae nosocomial infection.

It's recognized that patients with AGEP have revealed a high rate of positive patch tests when compared to patients with other types of cutaneous adverse reactions. In 2007, Seneschal et al. [6] reported patients who had experienced psoriasis form eruptions during antitumor necrosis factor therapy. The patients were patch tested with $30 \%$ etanercept and infliximab diluted in water or petroleum jelly. The diameters were measured after 48 hours and on the day 8 . The authors reported a positive patch test showing edema and vesicles in one patient. For this reason, they considered that patch test for diagnosing anti-TNF- $\alpha$ adverse reactions would be adequate. It is speculated that proteases are secreted in the stratum corneum and would cleave antiTNF- $\alpha$ in small fragments. Some authors [17] do not agree with the use of monoclonal antibodies for patch testing based on the concept that an allergen should have a molecular weight less than $500 \mathrm{Da}$ in order to succeed in passing through the epidermis layer. This could partially explain the negativity of the patch test in our patient. On the other hand, at the time the patch test with etanercept was performed, she was being treated with adalimumab. According to Rosmarin et al. [18], TNF- $\alpha$ blockers would not contraindicate patch testing in patients under use of other anti- TNF agents. Other authors $[6,7,19]$ also found negative results in patients with suspected adverse reaction to anti-TNF agents.

In conclusion, in daily medical practice, it is important to be alert to the possibility of serious skin reactions, such as AGEP, in patients using 
Citation: Vasconcelos LMF, Teixeira FM, Francelino EV, Almeida TLP, Chagas LB, et al. (2014) Acute Generalized Exanthematous Pustulosis in a 51-YearOld Patient under Etanercept Treatment for Psoriasis. J Pharmacovigilance 2: 120. doi:10.4172/2329-6887.1000120

etanercept. A correct diagnosis of drug allergy is necessary in order that appropriate therapeutic interventions be employed.

\section{Acknowledgement}

This study was financially supported by the CNPq (process 554970/2010-4) and CAPES.

\section{Conflicts of Interest}

The authors declare no conflicts of interest.

\section{References}

1. Pastore S, Gubinelli E, Leoni L, Raskovic D, Korkina L (2008) Biological drugs targeting the immune response in the therapy of psoriasis. Biologics 2: 687697.

2. Speeckaert MM, Speeckaert R, Lambert J, Brochez L (2010) Acute generalized exanthematous pustulosis: an overview of the clinical, immunological and diagnostic concepts. Eur J Dermatol 20: 425-433.

3. Halevy S (2009) Acute generalized exanthematous pustulosis. Curr Opin Allergy Clin Immunol 9: 322-328.

4. Moustou AE, Matekovits A, Dessinioti C, Antoniou C, Sfikakis PP, et al. (2009) Cutaneous side effects of anti-tumor necrosis factor biologic therapy: a clinical review. J Am Acad Dermatol 61: 486-504.

5. Teixeira FM, Vasconcelos LM, Rola Cde A, Prata de Almeida TL, Valença JT $\mathrm{Jr}$, et al. (2011) Secondary leprosy infection in a patient with psoriasis during treatment with infliximab. J Clin Rheumatol 17: 269-271.

6. Seneschal J, Lepreux S, Milpied B, Schaeverbeke T, Taïeb A (2007) Psoriasiform eruptions during anti TNF-alpha treatment: psoriasis or not? Arch Dermatol 143: 1593-1595.

7. Gonzalo-Garijo MA, Pérez-Calderón R, de Argila Fernández-Durán D (2008) Severe generalized exanthema due to etanercept given for severe plaque psoriasis. Ann Allergy Asthma Immunol 100: 621-622.
8. Williams VL, Cohen PR (2011) TNF alpha antagonist-induced lupus-like syndrome: report and review of the literature with implications for treatment with alternative TNF alpha antagonists. Int J Dermatol 50: 619-625.

9. McCain ME, Quinet RJ, Davis WE (2002) Etanercept and infliximab associated with cutaneous vasculitis. Rheumatology (Oxford) 41: 116-117.

10. Soliotis F, Glover M, Jawad AS (2002) Severe skin reaction after leflunomide and etanercept in a patient with rheumatoid arthritis. Ann Rheum Dis 61: 850 851.

11. Kavala M, Zindanci I, Turkoglu Z, Can B, Kocaturk E, et al. (2013) Acute generalized exanthematous pustulosis induced by etanercept: another dermatologic adverse effect. Case Rep Dermatol Med 2013: 601412.

12. Naranjo CA, Busto U, Sellers EM, Sandor P, Ruiz I, et al. (1981) A method for estimating the probability of adverse drug reactions. Clin Pharmacol Ther 30 : 239-245.

13. Barbaud A (1995) Place of excipients in drug-related allergy. Clin Rev Allergy Immunol 13: 253-263.

14. Sidoroff A, Halevy S, Bavinck JN, Vaillant L, Roujeau JC (2001) Acute generalized exanthematous pustulosis (AGEP)--a clinical reaction pattern. $J$ Cutan Pathol 28: 113-119.

15. Razera F, OIm GS, Bonamigo RR (2011) Neutrophilic dermatoses: part II. An Bras Dermatol 86: 195-209.

16. Leclair MA, Maynard B, St-Pierre C (2009) Acute generalized exanthematous pustulosis with severe organ dysfunction. CMAJ 181: 393-396.

17. Lecluse LL, Piskin G, Bos JD (2008) The use of patch tests in determining hypersensitivity to etanercept and infliximab. Arch Dermatol 144: 1070-1071.

18. Rosmarin D, Gottlieb AB, Asarch A, Scheinman PL (2009) Patch-testing while on systemic immunosuppressants. Dermatitis 20: 265-270.

19. Wee JS, White JM, McFadden JP, White IR (2010) Patch testing in patients treated with systemic immunosuppression and cytokine inhibitors. Contact Dermatitis 62: 165-169. 